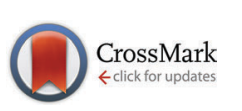

Cite this: Phys. Chem. Chem. Phys., 2015, 17, 24477

DOI: $10.1039 / c 5 c p 90156 a$

www.rsc.org/pccp

\section{Correction: A shock tube study of the branching ratios of propene $+\mathrm{OH}$ reaction}

\author{
Jihad Badra, ${ }^{\text {ab }}$ Fethi Khaled, ${ }^{a}$ Binod Raj Giri ${ }^{a}$ and Aamir Farooq ${ }^{* a}$ \\ Correction for 'A shock tube study of the branching ratios of propene $+\mathrm{OH}$ reaction' by Jihad Badra \\ et al., Phys. Chem. Chem. Phys., 2015, 17, 2421-2431.
}

The authors wish to acknowledge that some of the findings and text in this article were previously published in conference proceedings: Fethi B. Khaled, Jihad Barda, and Aamir Farooq, 50th AIAA/ASME/SAE/ASEE Joint Propulsion Conference, 2014, DOI: 10.2514/6.2014-3983. The article published in PCCP reports new experimental data and theoretical analysis to extract branching ratios of the propene $+\mathrm{OH}$ reaction. The article further extends the findings to calculate site-specific $\mathrm{H}$-abstractions rate coefficients for the butene $+\mathrm{OH}$ reaction.

The Royal Society of Chemistry apologises for these errors and any consequent inconvenience to authors and readers.

\footnotetext{
${ }^{a}$ Clean Combustion Research Center, Division of Physical Sciences and Engineering, King Abdullah University of Science and Technology (KAUST), Thuwal 23955, Saudi Arabia. E-mail: aamir.farooq@kaust.edu.sa; Tel: +966544700621

${ }^{b}$ Saudi Aramco Research and Development Center, Fuel Technology R\&D Division, Dhahran 31311, Saudi Arabia
} 